\title{
Bases iniciales para la restauración ecológica del pinabete en Jalapa
}

\author{
Gesly Anibal Bonilla Landaverry \\ Ingeniero Agrónomo, Maestro en Ciencias en Gestión Ambiental y \\ Doctor en Ciencias Políticas y Sociología \\ gesly77@hotmail.com \\ Centro Universitario de Sur Oriente \\ Universidad de San Carlos de Guatemala \\ Oscar Alfredo Sánchez Barrientos \\ Ingeniero Agrónomo \\ Dirección General de Investigación -DIGI- \\ Universidad de San Carlos de Guatemala
}

Fecha de recepción: 15/03/2017

Fecha de aceptación: 01/08/2017

\begin{abstract}
Resumen
La recuperación de bosques con presencia de pinabete Abies guatemalensis Rehder es de suma importancia para Jalapa. Con esta investigación se puede contar con información para sentar las bases iniciales para que se dé un proceso de restauración ecológica para el futuro, pues el pinabete es una especie endémica protegida. Crece en partes altas en cabeceras de cuenca, por lo que tiene un valor ecológico, ambiental y social inconmensurable. La restauración ecológica es una necesidad por las condiciones de deterioro que muchos ecosistemas tienen y el pinabete en Jalapa presenta fuertes amenazas como la tala ilícita, los incendios forestales y las actividades agropecuarias. Se estudiaron datos concretos para determinar la incidencia en los tomadores de decisión para su restauración. Se realizó una valoración de las plantas nodrizas como facilitadoras en el proceso de restauración ecológica. Se generó información y se dio seguimiento a las plantaciones previas del abeto en estudio. Se generaron datos vitales a considerar para la caracterización de condiciones hidrológicas y ecológicas de los bosques de pinabete; información sobre propiedades taxonómicas y botánicas en plantas nodrizas y análisis de suelos del área. Además se estimó el área total con presencia de pinabete.
\end{abstract}

\section{Palabras clave:}

Pinabete, medio ambiente, recarga hídrica, plantas nodrizas, restauración ecológica

\begin{abstract}
The recovery of forests with the presence of Abies guatemalensis Rehder is of paramount importance for Jalapa. This project as the main objective has laid the initial basis for an ecological restoration process for the future, as the Abies guatemalensis Rehder is a protected endemic species. It grows in high parts in headwaters of watershed, reason why it has an ecological, environmental and social value immeasurable. Ecological restoration is a necessity because of the deterioration conditions that many ecosystems have and the forest in Jalapa presents strong threats such as illegal logging, forest fires and agricultural activities. Specific data were studied to determine the impact on decision-makers for restoration. An evaluation of the suckling plants was made as facilitators in the process of ecological restoration. Information was generated and the previous plantations of the spruce under study were monitored. Vital data were generated to be considered for the characterization of hydrological and ecological conditions of forests Abies guatemalensis Rehder; Information on taxonomic and botanical properties in nursery plants and analysis of soils of the area. All this will benefit the environment and the people of this area.
\end{abstract}

\section{Keywords}

Pinabete, Environment, water recharge, nursery plants, ecological restoration 


\section{Introducción}

La restauración ecológica es sumamente importante para no perder especies endémicas como el pinabete Abies guatemalensis Rehder que se ve amenazado por la tala ilícita, incendios y principalmente por el inadecuado manejo forestal. Aunque la restauración ecológica supone un trabajo a largo plazo, las primeras acciones son de primordial importancia para que los resultados se vean años más tarde. En el país no hay lineamientos del Estado, como sí los hay en varios países de América Latina, sobre la restauración ecológica, por lo que es importante por medio de acciones concretas ir despertando la conciencia de la necesidad de este tipo de intervención. En varias partes del mundo hay ejemplos de proyectos exitosos de restauración ecológica y para Guatemala hay algunos casos que están procurando empezar con esta actividad, como el caso en Manglares donde se están llevando algunas experiencias como extensión del trabajo realizado en Chiapas, México. En la parte alta de San Marcos el Abies guatemalensis Rehder, algunos agricultores progresistas, con el objetivo de manejar estas especies como árbol de navidad, tienen experiencias de establecimiento utilizando criterios ecológicos. Un estudio realizado entre 2009 a 2011 en esta área sistematizó esas experiencias y proporcionó conocimiento sobre sucesión ecológica de 10 localidades de Ixchiguán, Tacaná, San José Ojetenam, Sibinal y San Marcos, alrededor de parches de bosque de Abies guatemalensis Rehder.

Sin embargo, en regiones del oriente de Guatemala es muy poca la experiencia que se tiene sobre restauración, principalmente en el departamento de Jalapa. A pesar que el Abies guatemalensis Rehder existe en las partes altas de este departamento no se tiene conciencia que esta especie se encuentra amenazada y en constante presión por la tala ilícita, el avance de actividades agropecuarias y los incendios forestales.

La comunidad que cuenta con pequeños bosques de pinabete es la aldea Soledad Grande del municipio de Mataquescuintla en el departamento de Jalapa. En esta aldea se cuenta con pocas experiencias exitosas para la reforestación del Abies guatemalensis Rehder a pesar que las condiciones climáticas y ecológicas son apropiadas para su propagación, no obstante la depredación y destrucción de los pocos bosques de Abies guatemalensis Rehder son cada vez más frecuentes, por la búsqueda de espacios para ganadería y agricultura, por lo que es imperante iniciar un proceso de restauración ecológica a partir de ecosistemas que han sido totalmente deteriorados principiando con la recuperación del suelo, el establecimiento de arbustos y en los años siguientes árboles.

Dentro de las actividades iniciales de una restauración ecológica se encuentran identificar y valorar el uso de las especies que pueden servir como nodrizas, y por lo tanto en este proyecto se está dando importancia a estos aspectos centrales que son clave para el establecimiento de los árboles. En el proceso de restauración ecológica es muy importante el seguimiento y monitoreo que va desde el inicio de la intervención, y que es mucho más importante cuando ya no hay proyecto, para que las mismas comunidades tengan una orientación de lo que sigue.

\section{Marco teórico}

\subsection{Restauración ecológica}

La mayoría de ecosistemas naturales en el mundo están deteriorados, esto ha traído consigo que de la diversidad biológica se hayan perdido o estén en peligro de extinción. Así las funciones normales de muchos ecosistemas también se han disminuido y en el peor de los casos desaparecido, por ejemplo la diversidad biológica, la producción de agua, la regulación del microclima, etc. Ante esto es necesario tomar acciones para recuperar en lo posible los ecosistemas dañados. Para esto inicialmente se debe eliminar o evitar al máximo el o los factores de deterioro, como la deforestación, el pastoreo, el cambio en el uso del suelo de prácticas no sostenibles y otros. Así los ecosistemas entran en un proceso de sucesión ecológica que a lo largo del tiempo se esperaría volviera a parecerse al ecosistema de referencia. Si este proceso es ayudado por el ser humano a través de utilizar prácticas acordes a procesos sucesionales, el tiempo de recuperación 
del ecosistema puede ser menor y a la vez puede propiciar el bienestar de sus servicios de tal forma que se vea la utilidad de realizar este trabajo.

La restauración ecológica de acuerdo con la Sociedad Internacional de Restauración Ecológica “...Es el proceso de ayudar al restablecimiento de un ecosistema que se ha degradado, dañado o destruido" (SER, 2004). El paradigma inicial de la restauración ecológica es que a través de este proceso se puede volver al ecosistema original, sin embargo la práctica ha demostrado que es difícil volver al mismo, lo cual es apoyado hoy por muchos autores (Clewel y Aronson, 2007). En el paradigma original las definiciones están orientadas por el objetivo final que es llegar al ecosistema de referencia, en tanto que lo que hoy se trabaja es hacer definiciones en función de procesos, por lo que el concepto de restauración debe ser más operacional y buscar que existan una estructura y función de ecosistema que indique que el sistema es autosostenible y que permita una mejor convivencia de la sociedad que en un ecosistema deteriorado, más que forzar a pretender alcanzar un ecosistema que existió en el pasado (Cairns y Heckman, 1996). De tal forma que un concepto más operacional de restauración ecológica sería visto como un proceso inducido por el ser humano para recuperar las condiciones ambientales (vegetación, flora, fauna, clima, agua, suelo y microorganismos) de un ecosistema perturbado (Jackson et al. 1995).

En este sentido es muy importante la participación comunitaria, de tal forma que la función del ecosistema debe ser percibida por la sociedad. Para esto desde el inicio, el análisis de la historia, condiciones actuales, actores principales, entre otros, debe ser importante, ya que si una comunidad no es informada e integrada en el plan de restauración, este difícilmente avanzará (Cardona, 2005). Hay conceptos que han sido utilizados paralelamente con el de restauración, como es el de rehabilitación, revegetación, reclamación y otros para los que se ha encontrado un uso de acuerdo con el grado de deterioro del ecosistema inicial y la proporción de estructura y función que se alcance, aunque etimológicamente no significan lo mismo (Vargas y Mora, 2007). El mejoramiento de la salud y la riqueza de los ecosistemas por medio de la restauración ecológica ha sido propuesto por varios autores (Winterhalder, Clewell y Aronson, 2004), y aunque estos términos son discutibles porque se han tomado de los utilizados en un organismo viviente, vale la pena considerarlos para evaluarlos con indicadores ecológicos (Davis y Slobodkin, 2004).

Las actividades realizadas para alcanzar los objetivos de la Restauración Ecológica deben estar enmarcadas dentro de la escala de modelos sucesionales ya que sirven para predecir cómo los proyectos de restauración alcanzan sus metas. En ese sentido se debe dar mayor énfasis a los procesos dinámicos de la composición de especies, diversidad y estructura que deben ser expresados como tasas de cambio (Parker, 1997).

En la restauración ecológica se deben tener en cuenta los procesos de escala y contexto de sitio, para diferenciar los efectos en áreas pequeñas y en niveles de paisaje, por otra parte también tomar en cuenta que muchos de los procesos en la trayectoria de la restauración ecológica puede en determinado momento ser dirigida por fuerzas externas, por ejemplo especies exóticas, que posiblemente cambien la ruta sucesional que pueda llevar al ecosistema de referencia (Parker, 1997; Apfelbaum y Haney, 2010).

Choi (2007), indica a la restauración ecológica como una nueva disciplina dentro de la ecología, que está proveyendo de nuevas formas de la conservación de la diversidad biológica, manejo de ecosistemas y prueba de teorías ecológicas. Para esto se deberán formular nuevos paradigmas basados en: a) establecimiento de ecosistemas que sean capaces de ser sustentables en el futuro y no basados en querer copiar ecosistemas del pasado ambiental, b) tener múltiples metas y trayectorias para puntos finales impredecibles de los ecosistemas, c) enfocarse sobre la rehabilitación de la función de los ecosistemas más que recomposición de especies o superficies cosméticas de paisaje y d) adquirir el conocimiento para identificar el valor agregado aplicado a la ciencia entre la parte económica y social inmersa en el tema. 
La restauración ecológica es una tarea práctica que procura llevar los conceptos de la ecología al plano de acción, como lo planteó Bradshaw (1987) la restauración ecológica es el test ácido de la ecología y por lo tanto se tiene que demostrar a través de sus acciones si los conceptos ecológicos son útiles, si no mucha de la teoría ecológica tendrá que cambiar en un futuro cercano.

Debe diferenciarse entre Ecología de la Restauración y Restauración ecológica. La primera sienta las bases y proporciona la teoría para efectuar la restauración, la segunda es la puesta en práctica de acciones de restauración con bases ecológicas (Palmer, Ambrose \& Poff, 1997).

\subsection{Principales pasos para la restauración ecológica}

El establecimiento de un plan de restauración ecológica, no es una receta pero sí hay algunos pasos importantes que deben considerarse para su aplicación. Por ejemplo Apfelbaum \& Haney (2010) proponen 10 pasos que en forma resumida son: 1) mapeo e inventario del área a restaurar; 2) investigación de la historia del paisaje donde está el ecosistema a intervenir; 3 ) interpretación de los cambios del paisaje; 4) desarrollo de objetivos y metas realistas; 5) preparación del plan; 6) desarrollo e inicio de un programa de monitoreo; 7) implementación del plan de restauración ecológico; 8) documentación de cambios y mantenimiento de registros; 9) reevaluación periódica del programa; 10) comunicación y educación.

Por su parte Vargas (2011) propone 13 pasos para la restauración ecológica, de la siguiente manera: 1) definir el ecosistema de referencia; 2) evaluar el estado actual del ecosistema; 3) definir los niveles y escalas de organización de la naturaleza, después de este punto se establecen los objetivos del proyecto; 4) establecer las jerarquías y escalas de disturbio; 5) consolidar la participación comunitaria; 6) evaluar el potencial de regeneración; 7) establecer los tensionantes para la restauración a diferentes escalas; 8) seleccionar las especies adecuadas para la restauración; 9) propagar y manejar las especies; 10) seleccionar los sitios; 11) diseñar estrategias para superar las barreras de la restauración; 12) monitorear el proceso de restauración; 13) consolidar el proceso de restauración.

\subsection{Atributos de los ecosistemas restaurados}

La Sociedad Internacional de Restauración Ecológica SER (2004), señala los siguientes atributos para los ecosistemas restaurados:

a) El ecosistema restaurado contiene un conjunto característico de especies que habitan en el ecosistema de referencia y que proveen una estructura apropiada de la comunidad.

b) El ecosistema restaurado consta de especies autóctonas hasta el grado máximo factible. En ecosistemas culturales restaurados, se puede ser indulgente con especies exóticas domesticadas y con especies ruderales, y arvenses que se supone que co-evolucionaron con ellas. Las especies ruderales son plantas que colonizan los sitios alterados; las especies arvenses típicamente crecen entre plantas de cultivo.

c) Todos los grupos funcionales necesarios para el desarrollo y/o la estabilidad continua del ecosistema restaurado se encuentran representados o, si no, los grupos faltantes tienen el potencial de colonizar por medios naturales.

d) El ambiente físico del ecosistema restaurado tiene la capacidad de sostener poblaciones reproductivas de las especies necesarias para la continua estabilidad o desarrollo a lo largo de la trayectoria deseada.

e) El ecosistema restaurado en apariencia funciona normalmente de acuerdo con su estado ecológico de desarrollo y no hay señales de disfunción.

f) El ecosistema restaurado se ha integrado adecuadamente con la matriz ecológica o el paisaje, con los cuales interactúa a través de flujos e intercambios bióticos y abióticos. 
g) Se han eliminado o reducido, tanto como sea posible, las amenazas potenciales del paisaje que lo rodea a la salud e integridad del ecosistema.

h) El ecosistema restaurado tiene suficiente capacidad de recuperación como para aguantar los acontecimientos estresantes periódicos y normales del ambiente local y que sirven para mantener la integridad del ecosistema.

i) El ecosistema restaurado es autosostenible al mismo grado que su ecosistema de referencia y tiene el potencial de persistir indefinidamente bajo las condiciones ambientales existentes. No obstante, los aspectos de su biodiversidad, estructura y funcionamiento podrían cambiar como parte del desarrollo normal del ecosistema y podrían fluctuar en respuesta a acontecimientos normales y periódicos aislados de estrés y de alteración de mayor trascendencia. Como con cualquier ecosistema intacto, la composición de las especies y otros atributos de un ecosistema restaurado podrían evolucionar a medida que cambian las condiciones ambientales.

\section{Materiales y métodos}

\subsection{Ubicación geográfica}

El área donde se llevó a cabo la presente investigación se encuentra en la aldea Soledad Grande, que pertenece al municipio de Mataquescuintla, del departamento de Jalapa, siendo uno de los 22 departamentos del país de Guatemala; dentro de

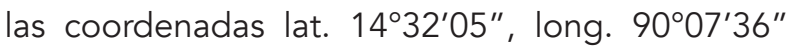
como se muestra en la figura 1. Esto debido a que es en esa aldea donde se encuentra la especie a estudiar. Las altitudes de la aldea oscilan entre los 2400 a 2800 msnm y presenta condiciones para el establecimiento de Abies guatemalensis Rehder con criterios de restauración ecológica.

Figura 1

Ubicación de la comunidad Soledad Grande

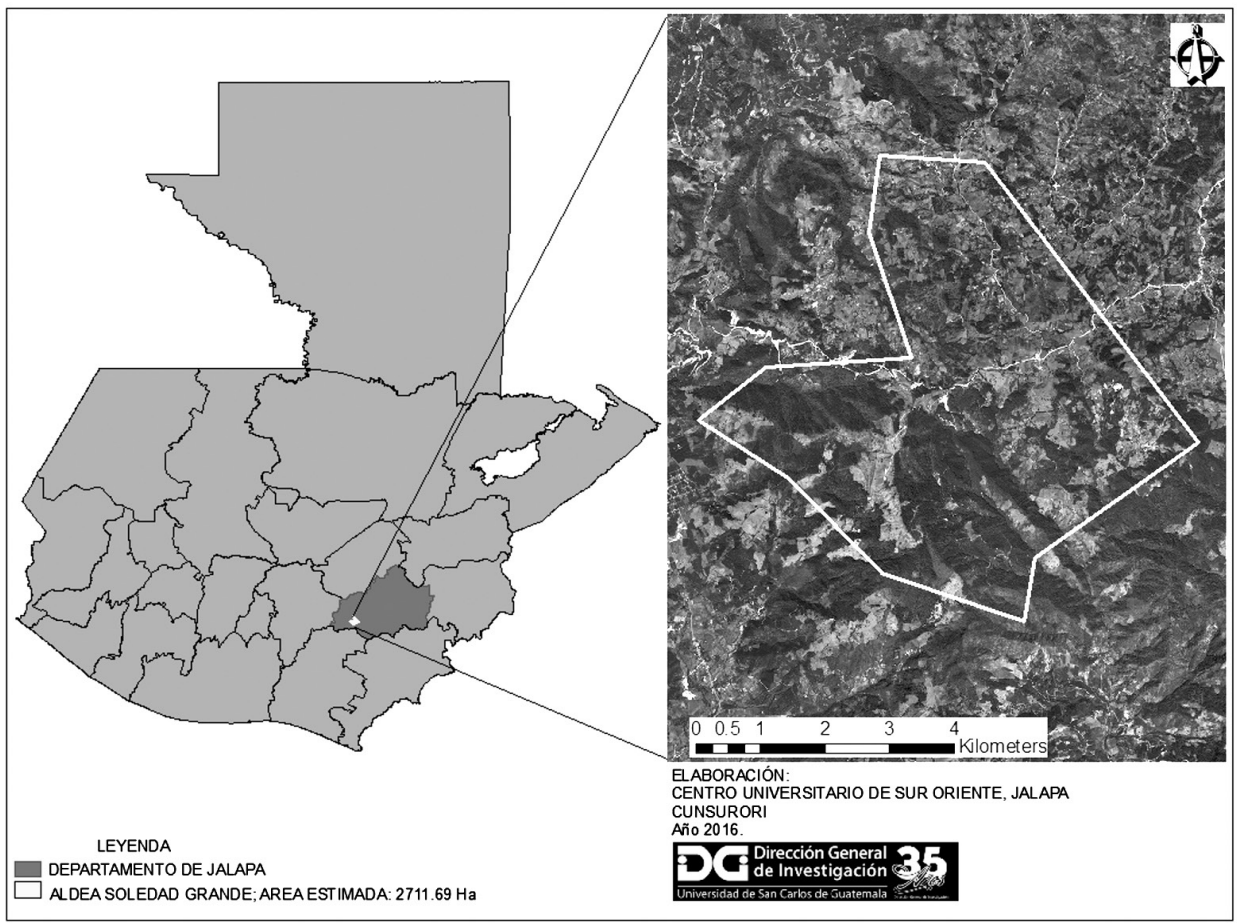




\subsection{Técnicas}

- $\quad$ Se recolectaron muestras de las potenciales especies que contribuyen al proceso de sucesión, tomando en cuenta factores físicos, tales como copa arbustiva, profundidad de raíz, cercanía de las especies al pinabete, indicando el buen desarrollo y crecimiento del mismo; así como también identificando las plantas nodrizas descritas en estudios anteriores en pinabete (Martínez 2013) que sirven como indicadores. Posterior a ello, se trasladaron a laboratorio para su identificación taxonómica.

- Por medio de análisis de laboratorio y levantamiento de calicatas, se obtuvo una caracterización física y química de los suelos. Analizando elementos mayores, menores, Capacidad de Intercambio Catiónico (CIC), Porcentaje de Saturación de Bases (\%SB), potencial de Hidrógeno $(\mathrm{pH})$, contenido de Materia Orgánica (MO), identificando los diferentes horizontes dentro de cada perfil contenido en los suelos.

- Se llevó a cabo un muestreo según indicaciones de la Unidad de Vinculación y Gestión de Recursos (Uviger) de la Facultad de la Universidad de San Carlos de Guatemala (FAUSAC) para posterior análisis de laboratorio, determinando así la presencia de hongos micorrícicos en el área donde esté presente el Abies guatemalensis Rehder y poder establecer una posible simbiosis entre ambas especies.

- Identificación y estimación del valor de los servicios ecosistémicos actuales y potenciales de los bosques de Abies guatemalensis Rehder de Jalapa. Destacando algunos servicios, la estimación de infiltración en suelos de bosques con presencia de pinabete, a través de cilindros de infiltración.

- Recopilación de datos a través de una estación meteorológica adquirida, para determinar características climáticas propias del área en estudio. Dicha estación meteorológica consta de instrumentos tales como termóme- tro, pluviómetro, higrómetro, anemómetro, veleta, entre otros.

- $\quad$ Se identificaron e inventariaron lotes en siembras de Abies guatemalensis Rehder, de lo cual se realizó un análisis de producción para árboles de navidad, realizando entrevistas a los propietarios.

- $\quad$ Se contabilizó el área natural existente de pinabete, a través de la medición de rodales, con la ayuda de gps, software de soporte, entre otros.

Analizando los diferentes aspectos de los objetivos anteriores, se plasmaron figuras de mapas dentro de los cuales se identifican las áreas que tienen potencial para restauración ecológica de pinabete, basándose en zonas de recarga hídrica, ubicación de plantas nodrizas, rangos altitudinales, entre otros. Con la ayuda de la literatura revisada, la cual especifica los criterios a seguir para recomendar una restauración de manera integral y con mayores posibilidades de éxito.

\section{Resultados}

\subsection{Especies arbustivas potenciales, plantas nodrizas que faciliten el crecimiento y desarrollo de pinabete}

\section{Saurauia sp}

Perteneciente a la familia de las Actinidiaceae. Comúnmente conocido como escobillo en Jalapa. Esta planta se caracteriza por crecer no más de los $1.5 \mathrm{~m}$, teniendo sus hojas de dos tonos en el as a la vez, teniendo verde y finalizando con café. Su sistema radicular es muy profundo, penetrando rara vez más de los $25 \mathrm{~cm}$ el suelo.

\section{Acaena elongata}

Perteneciente a la familia de las Rosaceae. En algunas áreas se le conoce como mozote de montaña, es una planta leñosa y herbácea, se caracteriza por presentar hojas alternas raramente opuestas, con flores solitarias y a menudo dispuestas en inflore- 
sencias, las mismas son poco vistosas, de textura espinosa cuando están maduras generalmete de color verde o café oscuro a rojo. Alcanza hasta una altura de 1 metro y se expanden en un radio no mayor de 2 metros cuadrados.

\section{Baccharis vaccinoides}

Es una planta arbustiva densamente ramificada, sus tallos son cortos y sus hojas son pequeñas y de consistencia dura, su máxima altura oscila entre 5.5 y hasta 6 metros máximo, su copa es de forma ovalada con diámetros que van desde 1.5 hasta 2.5 metros, sus flores se colocan en pequeños grupos al final de sus ramas y se puede utilizar con fines medicinales para el dolor de estómago y una buena digestión. Se conoce como Arrayan.

\section{Elaphoglossum guatemalense Klotz}

Perteneciente a la familia de las Lamariopsidaceae. Comúnmente se les conoce como lengua de venado; son helechos con hojas individuales de color verde y gruesas en el centro, que se originan desde la base del tronco donde empiezan las raíces de manera espesa y bifurcada, alcanza alturas hasta de $40 \mathrm{~cm}$.

\section{Malaxis lepidota (Finet) ames}

Son plantas vasculares, de color verde desde el tallo hasta las hojas, siendo estas opuestas y están ubicadas en pares, antecediéndole a las mismas un tallo delgado el cual posee en su parte posterior inflorescencias pequeñas de color rojizo y blanco, sus raíces son en forma de tubérculo de donde se desprenden muchas raíces absorbentes, su tamaño oscila entre 40 a 75 centímetros de largo y cubre radios aproximados de $80 \mathrm{~cm}$.

\section{Eryngium guatemalense Hemsi}

Es una planta que se caracteriza por tener muchas espinas, son plantas perennes, robustas, erectas, el tallo solitario, folioso, con hojas con múltiples aristas puntiagudas con una raíz axonomorfa pequeña. Hojas 20-45 × 2-4 cm ancho y de 40 hasta $75 \mathrm{~cm}$ de largo, linear-lanceoladas, espadiformes, la base escasamente atenuada, los márgenes callosos, densamente espinosos, ascendentes a reflexasnales.

\section{Solanum hartwegii Benth}

Es una especie arbustiva con espinas en las hojas y tallos. Es una planta perenne que alcanza alturas mayores a los dos metros. Se reproduce fácilmente y sus raíces son profundas. Sus tallos son semi leños y poco consistentes. Sus hojas son caducifolias. 


\section{2 Área existente de pinabete}

Figura 2

Área de bosque mixto con presencia de pinabete

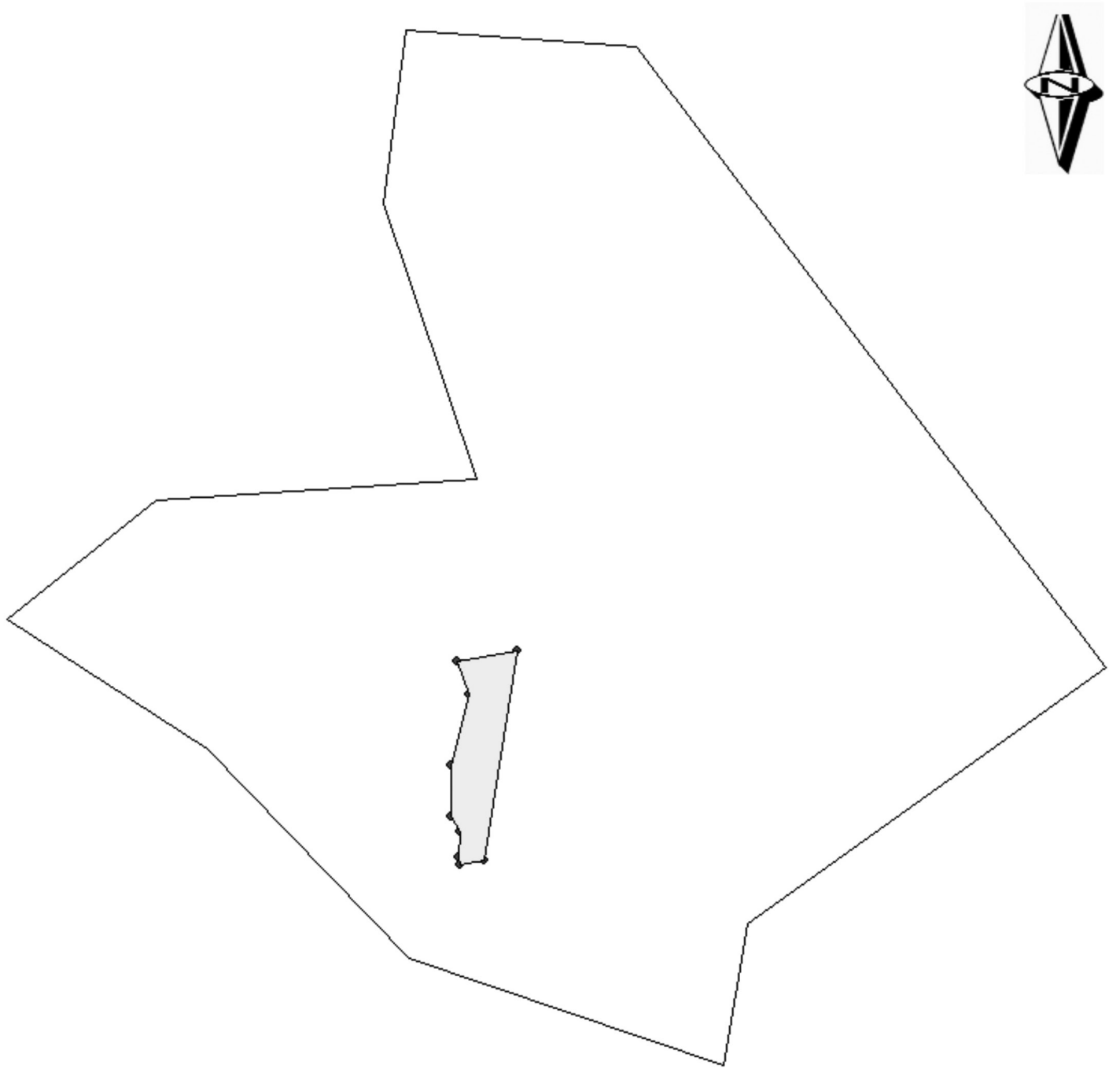

BOSQUE MIXTO CON PRESCENCIA DE PINABETE

AREA: $43.40 \mathrm{Ha}$

ELABORACIÓN:

CENTRO UNIVERSITARIO DE SUR ORIENTE, JALAPA CUNSURORI Año 2016.

\section{$\begin{array}{llll}00.276 .55 & 1.1 & 1.65 & 2.2\end{array}$}

Kilometers

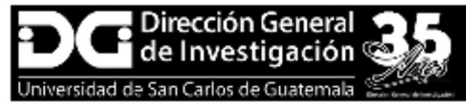

El área de bosque mixto con presencia de pinabete es de 43.40 ha. 
Figura 3

Área con árboles de pinabete dispersos

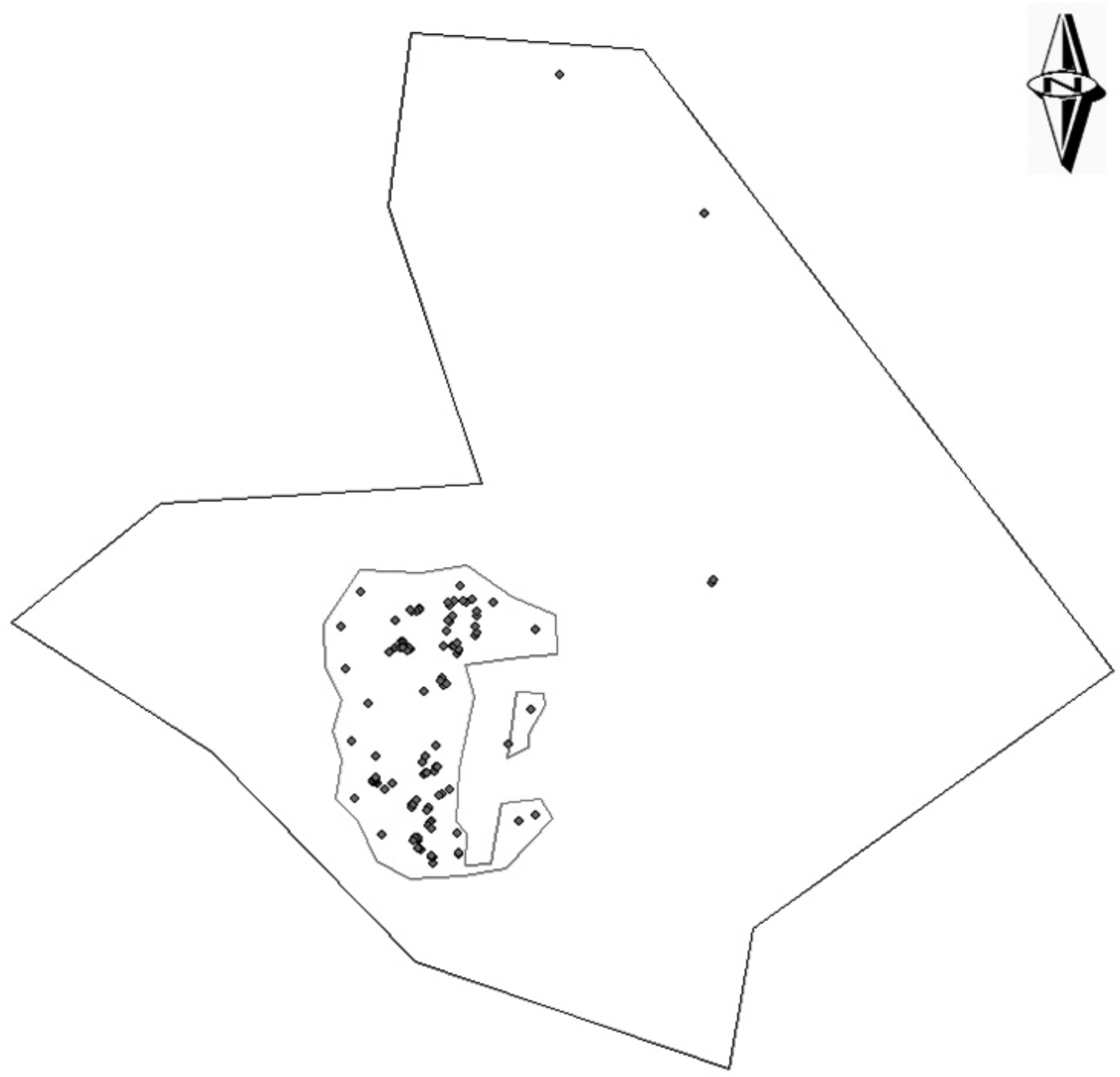

ARBOLES DISPERSOS

AREA: $231.38 \mathrm{Ha}$

$00.276 .55 \quad 1.1 \quad 1.65 \quad 2.2$

Kilometers
ELABORACION:

CENTRO UNIVERSITARIO DE SUR ORIENTE, JALAPA CUNSUROR

Año 2016.

El área con presencia de árboles de pinabete dispersos es de 231.38 ha. 
Figura 4

Área con plantaciones de pinabete

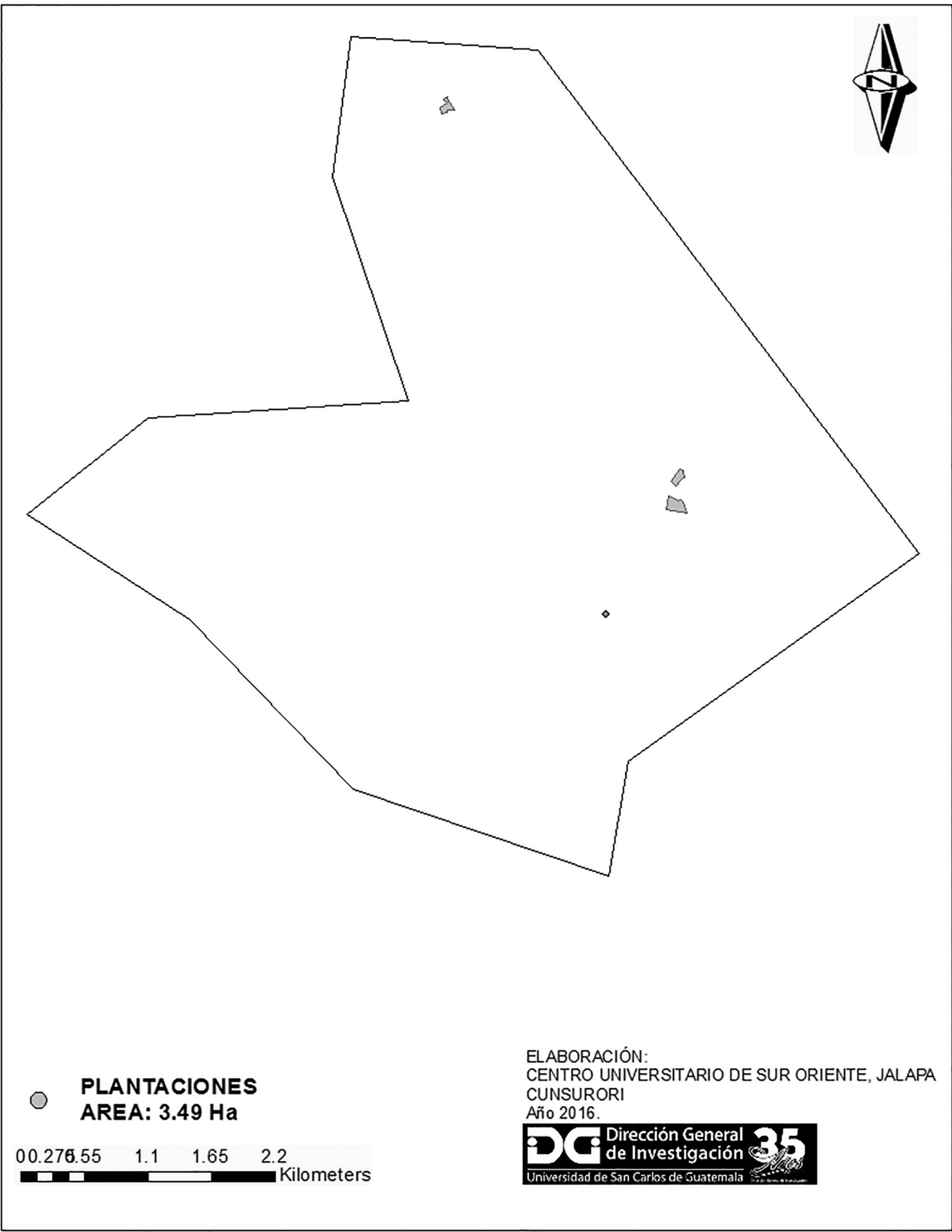

El área con plantaciones establecidas de pinabete es de 3.49 ha. 
Figura 5

Área con presencia de pinabete en la aldea Soledad Grande, Jalapa

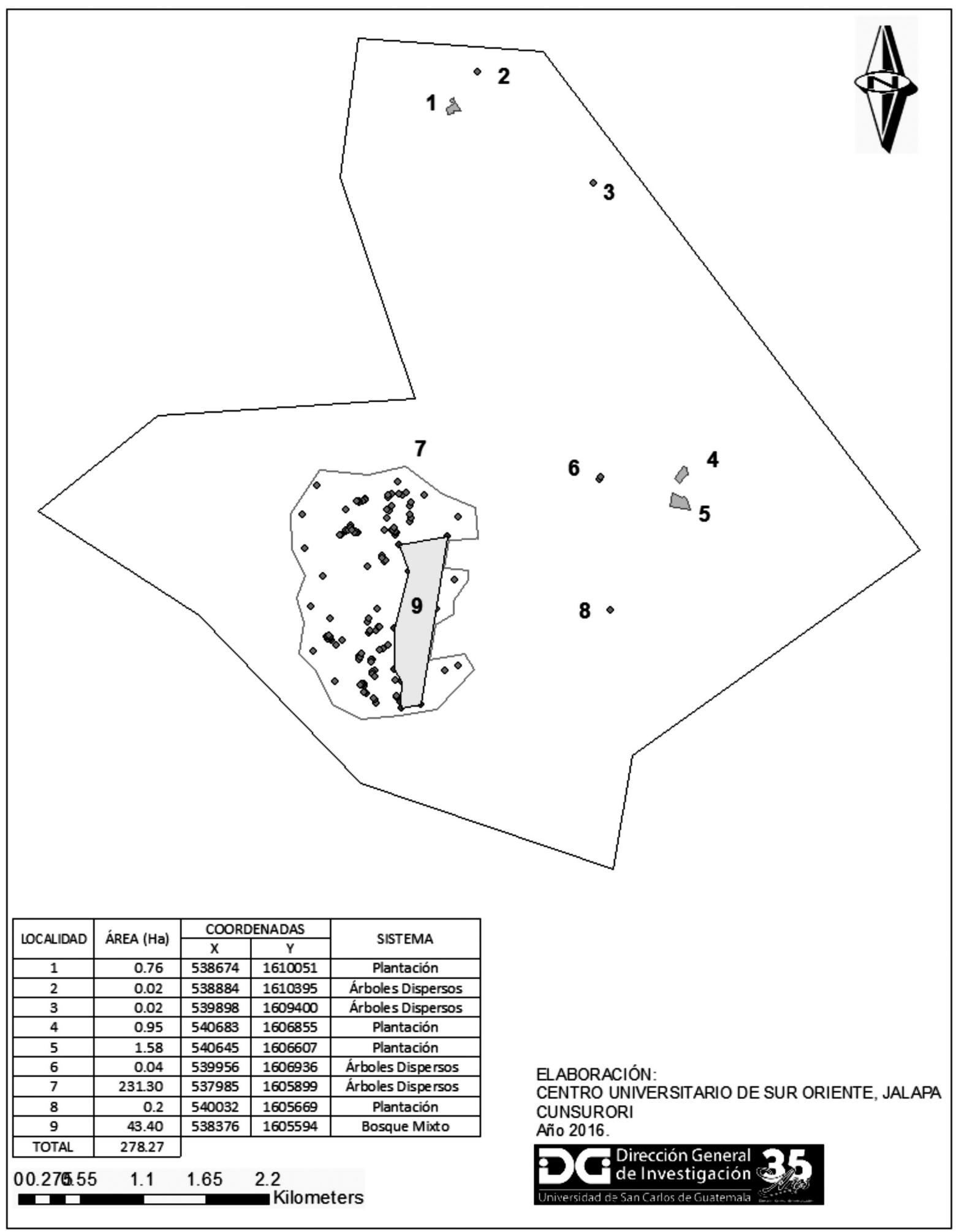

El total del área con presencia de pinabete es de 278.27 ha. 


\subsection{Análisis Micorrícico}

Dentro de las áreas con presencia de pinabete se identificó la existencia de hongos micorrícicos en el sistema radicular, de lo cual se confirma que el pinabete por ser una especie perteneciente a la familia Pinaceae posee cierta dependencia de la simbiosis existente entre ambas especies para la fijación de ciertos nutrientes para su desarroIlo. El porcentaje identificado asciende a un $84 \%$. Vale la pena resaltar que este análisis se realizó en el Centro de Diagnóstico Parasitológico de la Facultad de Agronomía de la Universidad de San Carlos de Guatemala.

\subsection{Datos climáticos}

Cabe mencionar que los datos climáticos generados fueron de los meses de noviembre y diciembre de 2016. Dentro de los datos climáticos que más destacan están las temperaturas promedio de $11^{\circ} \mathrm{C}$, humedad relativa de $70 \%$, velocidad del viento de $8 \mathrm{~km} / \mathrm{h}$, proveniente del norte; siendo estos datos comparados a los descritos según Martínez-Arévalo (2015) en la región occidente de gran similitud y aceptación para el desarrollo y crecimiento de dicha especie.

\subsection{Datos edáficos}

Las características de los suelos que se estudiaron son las siguientes: físicas, químicas e identificación de los diferentes horizontes del suelo por medio del estudio de perfiles de los mismos.

\section{- Características físico-químicas}

En lo que respecta al análisis químico de laboratorio, se muestrearon 2 fincas (El Carmen y Melgar) que se encuentran con mayor presencia de pinabete, dentro de dichas fincas se tomaron 3 muestras en base a las diferencias topográficas observadas, en donde elementos como el fósforo, cobre, zinc, hierro, sodio y potasio se mantuvieron en los mismos rangos con diferentes resultados, al igual que el $\mathrm{pH}$, la capacidad de intercambio catiónico, el porcentaje de la saturación de bases y el porcentaje de materia orgánica; mientras que los elementos como el manganeso, calcio y magnesio mostraron diferencias en más de algún sitio muestreado como se detalla en las tablas 1, 2 y 3 .

Tabla 1

Datos de laboratorio de análisis químico-físico finca El Carmen

\begin{tabular}{lcccccc}
\multicolumn{7}{c}{ Análisis químico } \\
\hline Bloque 1 & $\mathrm{pH}$ & $\mathrm{P}$ & $\mathrm{Cu}$ & $\mathrm{Zn}$ & $\mathrm{Fe}$ & $\mathrm{Mn}$ \\
\hline Rango medio & $6-6.5$ & $12-16$ & $2-4$ & $4-6$ & $10-15$ & $10-15$ \\
\hline Campo abierto & 5.5 & 1.22 & 0.50 & 4.00 & 5.50 & 4.50 \\
\hline Sotobosque & 5.1 & 0.98 & 0.10 & 4.50 & 5.00 & 21.50 \\
\hline Bloque 2 & & & & $\mathrm{meq} / 100 \mathrm{~g}$ & & \\
\hline Rango medio & & $\mathrm{CIC}$ & $\mathrm{Ca}$ & $\mathrm{Mg}$ & $\mathrm{Na}$ & $\mathrm{K}$ \\
\hline Campo abierto & & $20-25$ & $4-8$ & $1.5-2$ & --- & $0.27-0.38$ \\
\hline Sotobosque & & 48.55 & 5.24 & 0.99 & 0.10 & 1.15 \\
\hline
\end{tabular}

Continúa... 


\begin{tabular}{|c|c|c|c|c|}
\hline \multicolumn{5}{|c|}{ Análisis químico } \\
\hline Bloque 3 & \multicolumn{3}{|c|}{ SB } & M.O. \\
\hline Rango medio & \multicolumn{3}{|c|}{$75-90$} & $4-5$ \\
\hline Campo abierto & \multicolumn{3}{|c|}{15.42} & 12.96 \\
\hline Sotobosque & \multicolumn{3}{|c|}{35.09} & 12.52 \\
\hline \multicolumn{5}{|l|}{ Análisis físico } \\
\hline \multirow[t]{2}{*}{ Bloque 4} & \multicolumn{3}{|c|}{$\%$} & Clase textural \\
\hline & Arcilla & Limo & Arena & \\
\hline Campo abierto & 10.46 & 35.32 & 54.22 & Franco Arenoso \\
\hline Sotobosque & 14.66 & 24.82 & 60.52 & Franco Arenoso \\
\hline
\end{tabular}

Fuente: Elaboración propia.

Tabla 2

Datos de laboratorio de análisis químico-físico finca Melgar

\begin{tabular}{|c|c|c|c|c|c|c|}
\hline \multicolumn{7}{|c|}{ Análisis químico } \\
\hline \multirow[t]{2}{*}{ Bloque 1} & & \multicolumn{5}{|c|}{ Ppm } \\
\hline & $\mathrm{pH}$ & $P$ & $\mathrm{Cu}$ & $\mathrm{Zn}$ & $\mathrm{Fe}$ & $\mathrm{Mn}$ \\
\hline Rango Medio & $6-6.5$ & $12-16$ & $2-4$ & $4-6$ & $10-15$ & $10-15$ \\
\hline \multirow[t]{2}{*}{ Bosque Melgar } & 5.0 & 1.06 & 0.10 & 5.00 & 9.50 & 26.00 \\
\hline & & \multicolumn{5}{|c|}{ meq $/ 100 \mathrm{~g}$} \\
\hline Bloque 2 & & $\mathrm{CIC}$ & $\mathrm{Ca}$ & $\mathrm{Mg}$ & $\mathrm{Na}$ & $\mathrm{K}$ \\
\hline Rango medio & & $20-25$ & $4-8$ & $1.5-2$ & --- & $0.27-0.38$ \\
\hline \multirow[t]{2}{*}{ Bosque Melgar } & & 37.03 & 12.23 & 3.29 & 0.17 & 2.05 \\
\hline & & \multicolumn{5}{|c|}{$\%$} \\
\hline Bloque 3 & & \multicolumn{3}{|c|}{ SB } & \multicolumn{2}{|c|}{ M.O. } \\
\hline Rango medio & & \multicolumn{3}{|c|}{$75-90$} & \multicolumn{2}{|c|}{$4-5$} \\
\hline Bosque Melgar & & \multicolumn{3}{|c|}{47.91} & \multicolumn{2}{|c|}{10.98} \\
\hline \multicolumn{7}{|l|}{ Análisis físico } \\
\hline \multirow[t]{2}{*}{ Bloque 4} & \multicolumn{3}{|c|}{$\%$} & \multicolumn{3}{|c|}{ Clase textural } \\
\hline & Arcilla & Limo & Arena & & & \\
\hline Bosque Melgar & 18.85 & 26.92 & 54.22 & & Oo Arenoso & \\
\hline
\end{tabular}

Con lo que concierne al análisis físico, el resultado corresponde a una clase textural de un suelo franco arenoso, lo cual nos indica que posee buen drenaje y una ideal capacidad para dar sostenibi- lidad al sistema radicular que es el encargado del anclaje de las plantas, teniendo la característica de poder retener una cantidad de agua adecuada y aireación aceptable. 
Tabla 3

Rangos asignados a elementos y pH del suelo con pinabete, basados en tablas de Bernier (2014)

\begin{tabular}{llll} 
& \multicolumn{1}{c}{ Campo abierto } & \multicolumn{1}{c}{ Sotobosque } & \multicolumn{1}{c}{ Bosque Melgar } \\
$\mathrm{P}$ & Muy bajo & Muy bajo & Muy bajo \\
$\mathrm{Ca}$ & Medio & Adecuado & Adecuado \\
$\mathrm{Mg}$ & Muy bajo & Alto & Alto \\
$\mathrm{K}$ & Alto & Alto & Alto \\
$\mathrm{Na}$ & Muy bajo & Muy bajo & Bajo \\
$\mathrm{pH}$ & Muy fuertemente ácido & Fuertemente ácido & Fuertemente ácido \\
\hline
\end{tabular}

Fuente: Elaboración propia

- Identificación de perfiles

En relación con los resultados del estudio geotécnico de suelos con presencia de pinabete en la aldea Soledad Grande, se llevó a cabo por medio del método directo. Basándose en la metodología de Rossiter (2002) se estableció que son suelos profundos, ya que según Rossiter se le denominan de esta manera a los suelos en donde la roca madre se encuentra a profundidades mayores de $1.25 \mathrm{~m}$.

Tabla 4

Profundidad de suelos con presencia de pinabete

\begin{tabular}{|c|c|c|}
\hline Calicata \# & Coordenadas & Profundidad/roca madre \\
\hline 1 & $\begin{array}{c}\text { N } 14^{\circ} 31^{\prime} 04^{\prime \prime} \\
\text { W } 90^{\circ} 08^{\prime} 20.2^{\prime \prime}\end{array}$ & $>1.5 \mathrm{~m}$ \\
\hline 2 & $\begin{array}{c}\text { N } 14^{\circ} 30^{\prime} 56.9^{\prime \prime} \\
\text { W } 90^{\circ} 05^{\prime} 3^{\prime \prime}\end{array}$ & $>1.5 \mathrm{~m}$ \\
\hline 3 & $\begin{array}{l}\text { N } 14^{\circ} 31^{\prime} 00 .^{\prime \prime} \\
\text { W } 90^{\circ} 08^{\prime} 43.2^{\prime \prime}\end{array}$ & $>1.5 \mathrm{~m}$ \\
\hline 4 & $\begin{array}{l}\text { N } 14^{\circ} 31^{\prime} 15 . " \\
\text { W } 90^{\circ} 08^{\prime} 40^{\prime \prime}\end{array}$ & $>1.5 \mathrm{~m}$ \\
\hline 5 & $\begin{array}{l}\text { N } 14^{\circ} 34^{\prime} 20 . " \\
\text { W } 90^{\circ} 07^{\prime} 39^{\prime \prime}\end{array}$ & $>1.5 \mathrm{~m}$ \\
\hline
\end{tabular}

Fuente: Elaboración propia

\subsection{Datos Hidrológicos}

Se llevaron a cabo estudios hidrológicos de manera sectorizada, ya que la zona en estudio cuenta con una cantidad considerable de afluentes de agua, lo cual hizo imposible realizar dichos estudios en todos los afluentes, los datos obtenidos son de aforos e infiltración básica: 
- Aforo

Se coordinaron aforos de manera estratégica para establecer el caudal proveniente de los nacimientos en bosques de pinabete. Los resultados se describen.

\section{Tabla 5}

Datos del tiempo y volumen de 3 nacimientos por el método volumétrico

\begin{tabular}{|cccc}
\hline Aforo 1 & Aforo 2 & Aforo 3 & \\
\hline Tiempo & Tiempo & Tiempo & Volumen \\
\hline $24.76 \mathrm{~s}$ & $1.68 \mathrm{~s}$ & $1.09 \mathrm{~s}$ & $8 \mathrm{~L}$ \\
\hline $24.33 \mathrm{~s}$ & $1.63 \mathrm{~s}$ & $1.43 \mathrm{~s}$ & $8 \mathrm{~L}$ \\
\hline $23.36 \mathrm{~s}$ & $1.87 \mathrm{~s}$ & $1.40 \mathrm{~s}$ & $8 \mathrm{~L}$ \\
\hline $25.11 \mathrm{~s}$ & $1.71 \mathrm{~s}$ & $1.42 \mathrm{~s}$ & $8 \mathrm{~L}$ \\
\hline $24.19 \mathrm{~s}$ & $1.60 \mathrm{~s}$ & $1.39 \mathrm{~s}$ & $8 \mathrm{~L}$ \\
& $1.50 \mathrm{~s}$ & $1.21 \mathrm{~s}$ & $8 \mathrm{~L}$ \\
& $1.53 \mathrm{~s}$ & $1.52 \mathrm{~s}$ & $8 \mathrm{~L}$ \\
\hline & $1.54 \mathrm{~s}$ & $1.39 \mathrm{~s}$ & $8 \mathrm{~L}$ \\
\hline & & $1.45 \mathrm{~s}$ & $8 \mathrm{~L}$ \\
\hline
\end{tabular}

$\mathrm{Q}($ caudal $)=$ volumen $/$ tiempo

Aforo 1.

$\mathrm{Q}=8 \mathrm{~L} / 24.35 \mathrm{~s}$

$\mathrm{Q}=0.33 \mathrm{~L} / \mathrm{s}$

Aforo 2 .

$\mathrm{Q}=8 \mathrm{~L} / 1.63 \mathrm{~s}$

$\mathrm{Q}=4.912 \mathrm{~L} / \mathrm{s}$

Aforo 3.

$\mathrm{Q}=8 \mathrm{~L} / 1.37 \mathrm{~s}$

$\mathrm{Q}=5.84 \mathrm{~L} / \mathrm{s}$

Tabla 6

Datos utilizando el método sección velocidad para aforar el cauce principal de los nacimientos

\begin{tabular}{ccc} 
Sección & Profundidad & Tiempo \\
\hline 1 & $18 \mathrm{~cm}$ & $19.30 \mathrm{~s}$ \\
\hline 2 & $25 \mathrm{~cm}$ & $16.86 \mathrm{~s}$ \\
\hline 3 & $26 \mathrm{~cm}$ & $18.39 \mathrm{~s}$ \\
\hline 4 & $19 \mathrm{~cm}$ & $18.73 \mathrm{~s}$ \\
\hline 5 & $24 \mathrm{~cm}$ & $18.33 \mathrm{~s}$ \\
\hline 6 & $18 \mathrm{~cm}$ & $17.52 \mathrm{~s}$ \\
\hline
\end{tabular}

Fuente: Elaboración propia
Perfil de la corriente principal

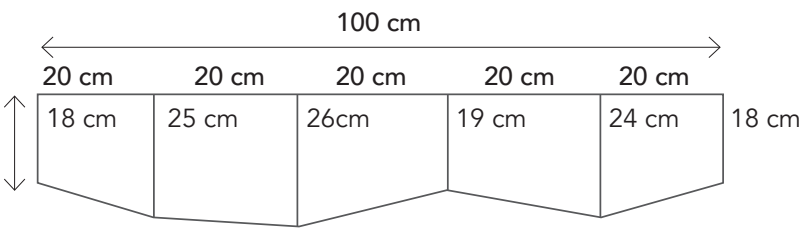

Área del Río

$$
\begin{aligned}
& \text { A total }=\mathrm{A} 1+\mathrm{A} 2+\mathrm{A} 3+\mathrm{A} 4+\mathrm{A} 5+\mathrm{A} 6 \\
& \mathrm{~A} 1=\frac{0.18+0.25}{2} * 0.20=0.043 \mathrm{~m}^{2} \\
& \mathrm{~A} 2=\frac{0.25+0.26}{2} * 0.20=0.051 \mathrm{~m}^{2} \\
& \mathrm{~A} 3=\frac{0.26+0.19}{2} * 0.20=0.045 \mathrm{~m}^{2} \\
& \mathrm{~A} 4=\frac{0.19+0.24}{2} * 0.20=0.043 \mathrm{~m}^{2} \\
& \mathrm{~A} 5=\frac{0.24+0.18}{2} * 0.20=0.042 \mathrm{~m}^{2} \\
& \text { Área total }=0.224 \mathrm{~m}^{2} \\
& \text { Velocidad de desplazamiento } \\
& \text { Velocidad }=\text { Distancia / Tiempo } \\
& \text { Velocidad }=\frac{5 \text { metros }}{17.52 \text { segundos }}=0.285 \mathrm{~m} / \mathrm{s}
\end{aligned}
$$

\section{- Infiltración básica}

Se realizaron pruebas de infiltración básica dentro del área con presencia de pinabete; identificando 2 áreas como punto de partida, las cuales son sotobosque y campo abierto. La primera como su nombre lo indica, es el área donde existe una densidad considerable de vegetación, y la segunda, es un área con poca presencia de vegetación, que en su mayoría de espacio se encuentran algunos árboles dispersos, esto debido a que la infiltración posee una variación en ambientes de esta naturaleza. El comportamiento de la velocidad de infiltración se muestra en la Gráfica 1. 


\section{Gráfica 1}

\section{Velocidad de infiltración por el método de doble cilindro}

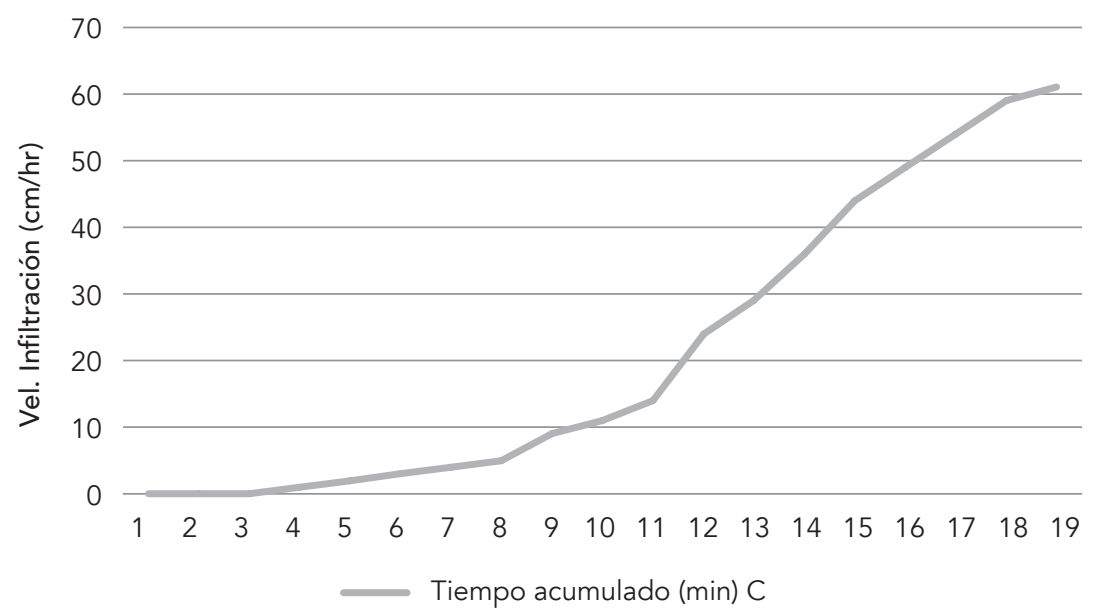

Fuente: Elaboración propia

La Gráfica 1 muestra que la infiltración en campo abierto es pronunciada en la primera hora. Sin embargo, al llegar a capacidad de campo el suelo se satura y el proceso de infiltración se detiene de- bido a que no existe mayor cobertura vegetal. En cuanto a la velocidad de infiltración en sotobosque el comportamiento se muestra en la Gráfica 2.

\section{Gráfica 2}

Velocidad de infiltración sotobosque método de doble cilindro

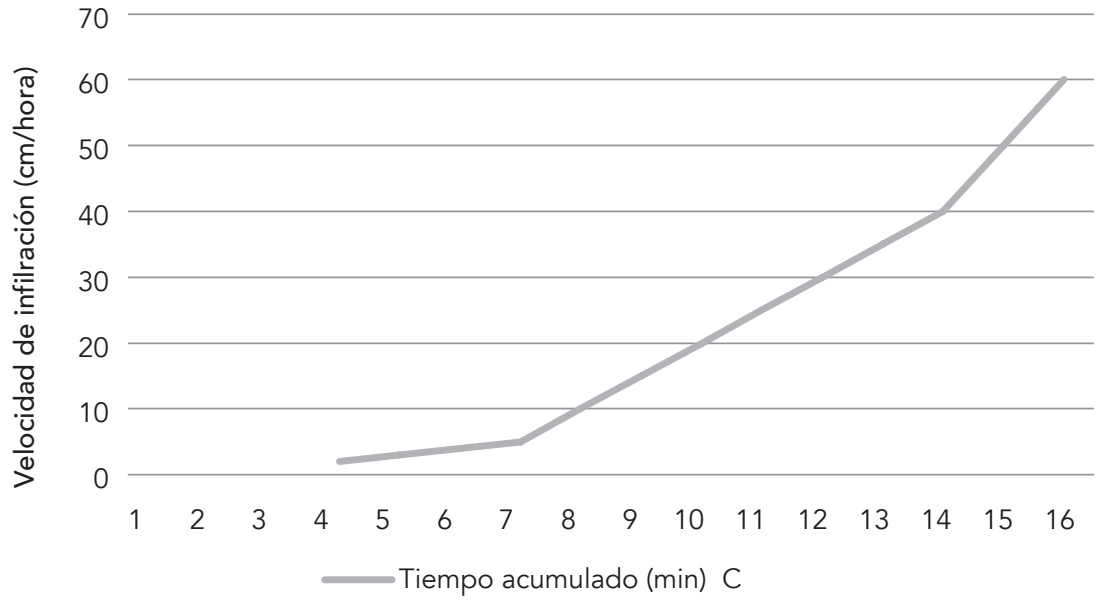

Fuente: Elaboración propia

Cuando existe vegetación en el suelo, la infiltración se da de manera uniforme y es constante después de una hora de tiempo, por lo que se puede inferir que en los bosques de pinabete el sotobosque juega un papel preponderante para la recarga hídrica. 


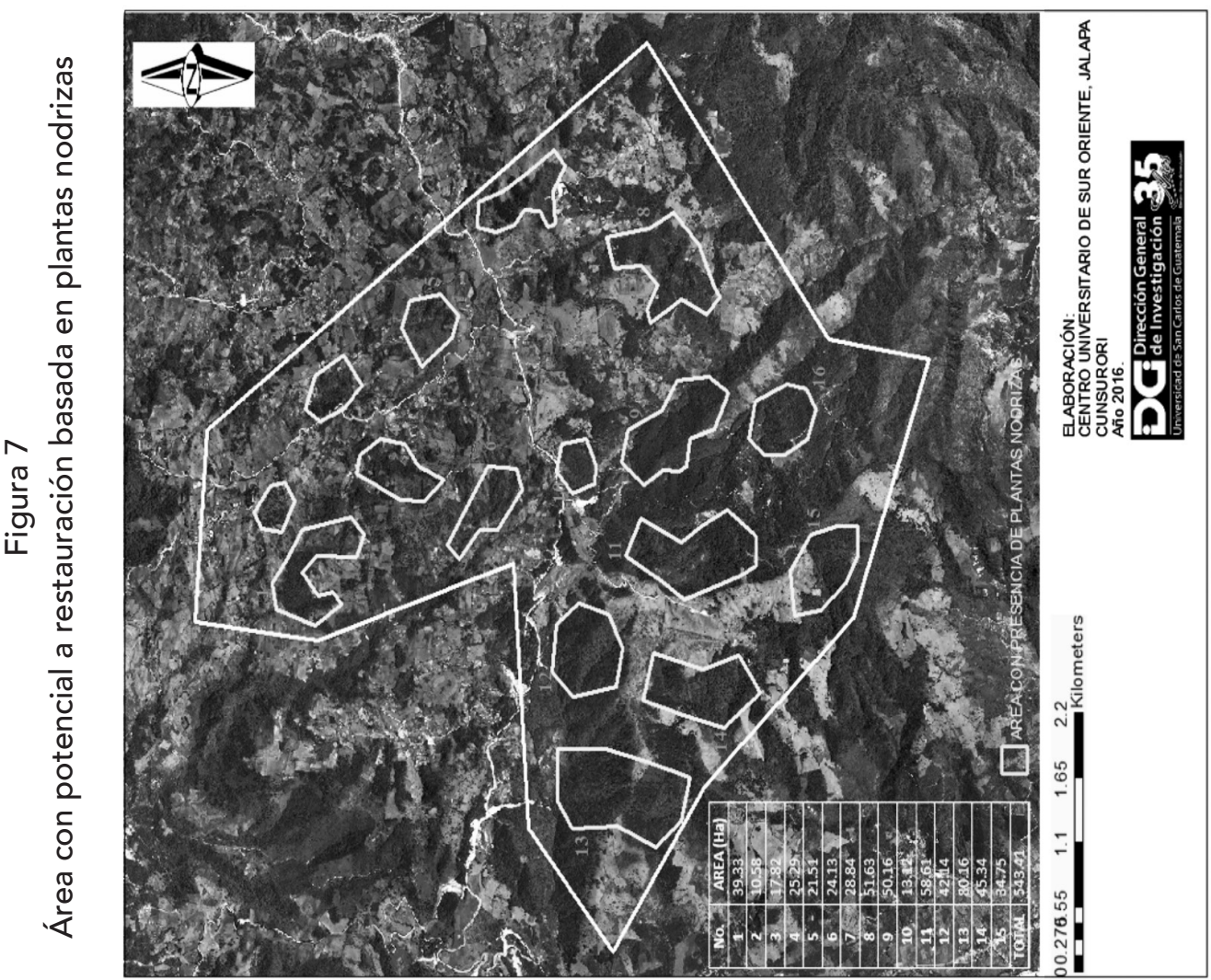

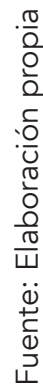

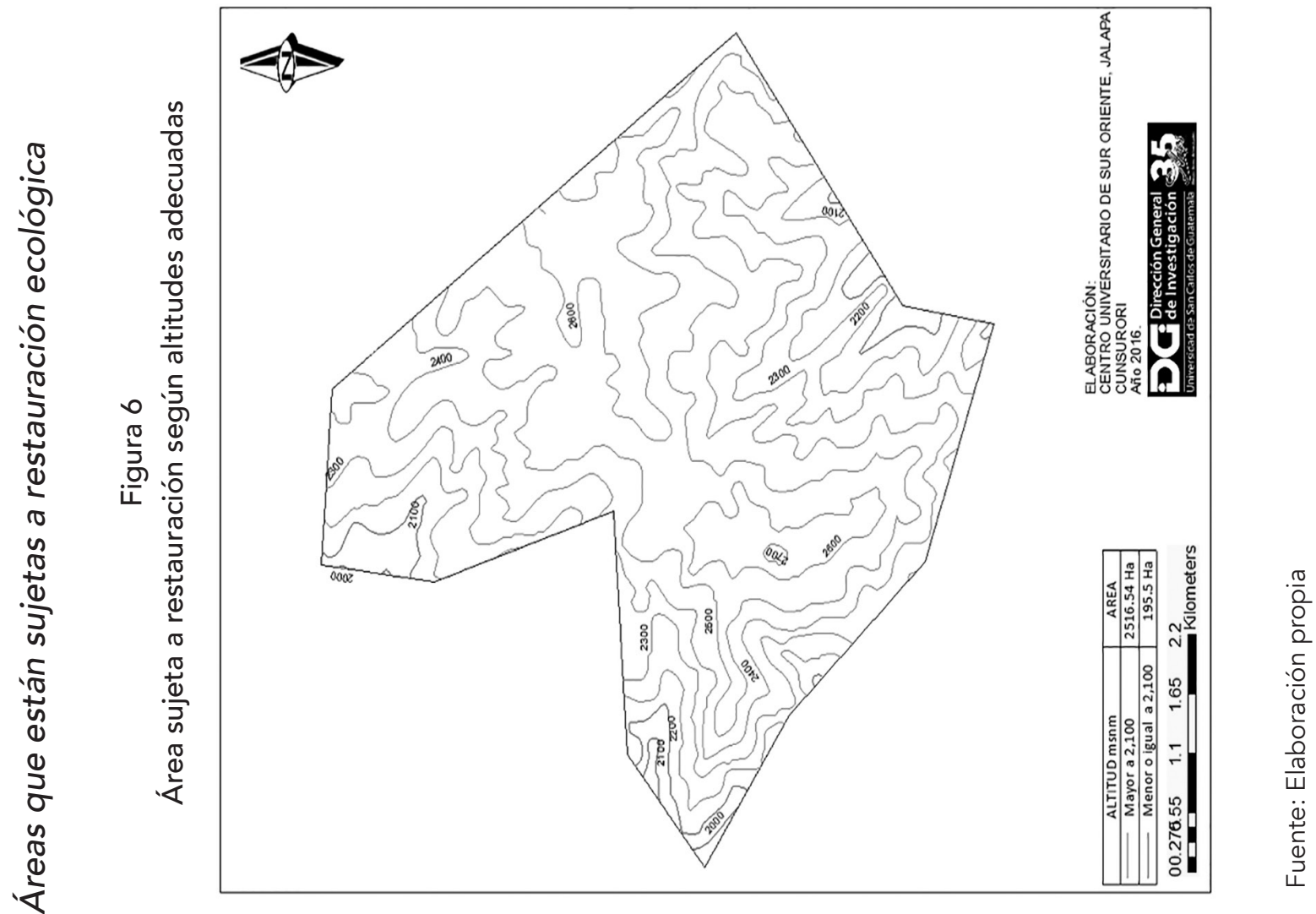


Un aspecto muy importante a tomar en cuenta es que toda el área de la aldea Soledad Grande es la parte más alta del departamento de Jalapa, por consiguiente, es cabecera de cuenca de ríos, riachuelos, quebradas y diversos nacimientos (algu- nos se encuentran fuera de la aldea) que dependen de gran manera de la cobertura forestal, la cual sirve de gran ayuda para las zonas de recarga hídrica. Por consiguiente, toda la zona es apta para restauración ecológica del pinabete.

Figura 8

Red hídrica de la aldea Soledad Grande, Jalapa

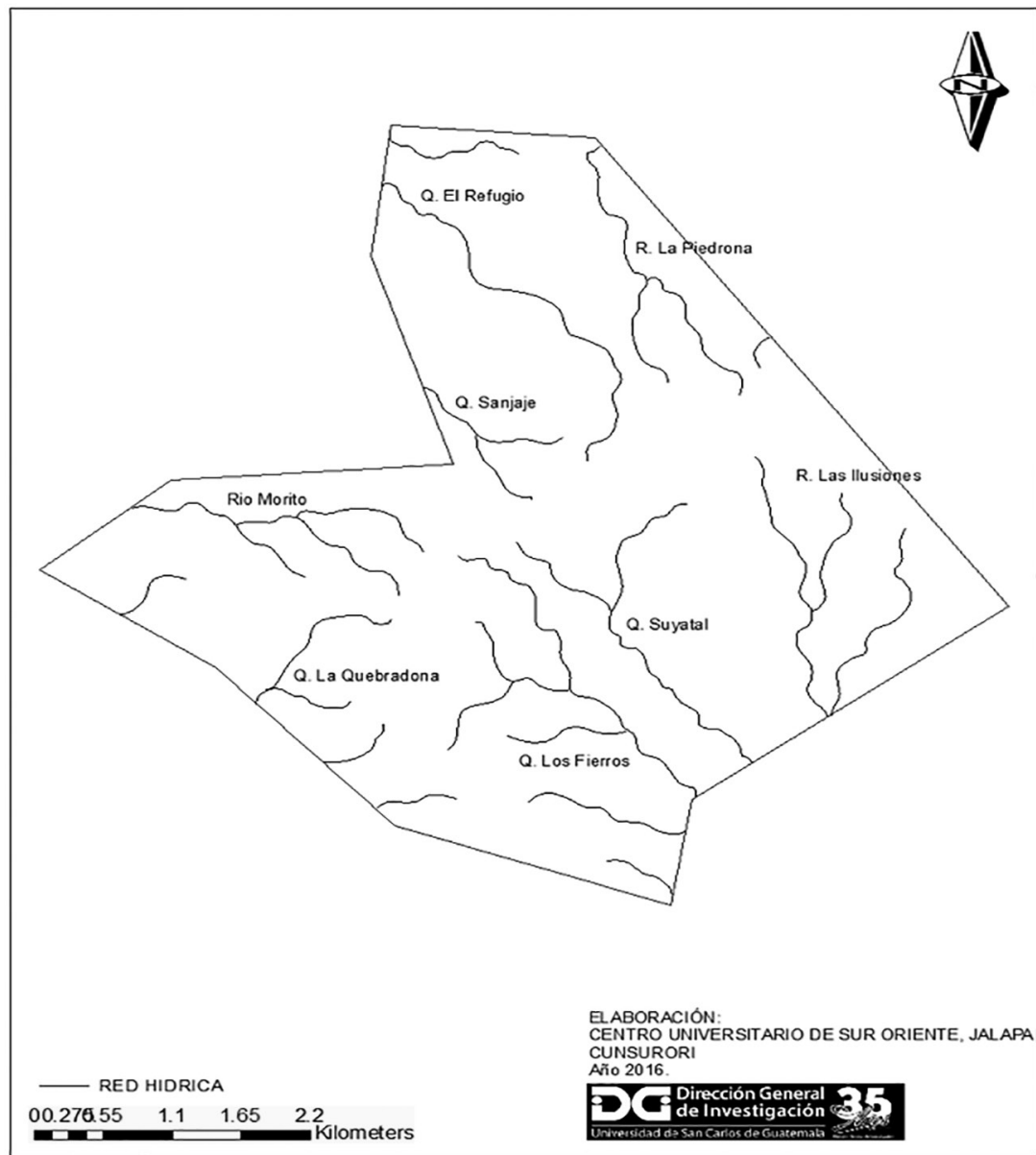

Fuente: Elaboración propia

\section{Análisis y discusión de resultados}

El número de plantas que se identificaron como potenciales nodrizas son seis; esto debido a que se hicieron comparaciones con las descritas por Martínez-Arévalo (2015) en el estudio realizado sobre conocimiento de seis especies arbustivas utilizadas como plantas nodrizas en el occidente de Guatemala. Encontrando similitudes entre las que él describe, con algunas encontradas en el área con cobertura de pinabete.

El área existente de pinabete es pequeña (278.27 ha) en comparación con las más de 25,000 ha que se encuentran en occidente (Martínez 2013), no por ello se debe menospreciar o dejar de atender la recuperación y ampliación del pinabete en Jalapa, ya que los servicios y beneficios que se obtendrían serían de 
suma importancia para el departamento. La reducción del pinabete se ha debido a diversos factores, uno de ellos es que en occidente se cuenta con mayores áreas disponibles en relación con las altitudes encontradas, que es el factor principal a tomar en cuenta para establecer el pinabete. Otro factor es el avance de la frontera agrícola y silvopastoril que durante años se realizó sin conciencia alguna del daño que se le ocasionó al pinabete; este fenómeno está cambiando, ya que muchos de los dueños de fincas con grandes extensiones, pretenden recuperar gran parte del área que estuvo cubierta con pinabete. De igual forma el Estado ha creado incentivos que poco a poco han motivado a los propietarios a extender las áreas con pinabete; lo cual tuvo mayor eco con la presencia del equipo de investigación que hizo conciencia de los beneficios que se obtienen a nivel económico y ambiental. Otro factor a tomar en cuenta dentro de los bosques de pinabete que ha mermado la prosperidad de la especie, es el poco ingreso de luz al área, lo cual limita el proceso de fotosíntesis en plantas de menor tamaño y hace que no puedan subsistir dichas plantas.

En relación al alto contenido de micorrizas encontrado en los sistemas radiculares del pinabete, tiene relación directa con un bajo contenido de fósforo encontrado en los estudios de suelos realizados; ya que la baja disponibilidad de dicho elemento obliga depender de las micorrizas para poder aprovecharlo. Esto según Álvarez-Sanchez et al (2013) son factores que coinciden en la mayoría de los casos.

El contenido de Materia Orgánica (MO) encontrado en las 3 muestras es elevado (tablas 1 y 2), siendo mayor al rango promedio sugerido por Uviger; según Pinochet (1991) esto se debe a que son suelos forestales con alta presencia de coníferas, característico de ellos. Algo muy favorable para que se conserven y protejan dichos bosques; éste proceso de descomposición es importante que no se detenga, ya que aumenta las condiciones favorables para un mejor proceso de restauración del pinabete. Su alto contenido de materia orgánica se debe en gran parte a la lenta incorporación y descomposición de residuos orgánicos que en su mayoría pertenecen a la vegetación existente; el cual es un atributo característico de los bosques mixtos con presencia de abetos (Bello \& López-Mata 2001).

Según tablas presentadas por Bernier (2014) en su revista sobre recuperación de suelos degradados y comparando con los resultados en esta investigación se tiene el fósforo (P) como "Muy bajo", para el calcio (Ca) un rango "adecuado", el Magnesio $(\mathrm{Mg})$ se presenta en rango "alto", así también se determinó un rango "alto" para el Potasio (K) y "muy bajo" para el sodio ( $\mathrm{Na}$ ); el pH del suelo en el bosque donde crece pinabete en la aldea que es campo de estudio se domina el rango "fuertemente ácido". Siendo este un proceso de acidificación en el suelo que se ha dado a través de los años, que a su vez incide en la mayoría de los casos de manera directa en un porcentaje bajo en la Saturación de las Bases (SB), esto según Morón \& La Estanzuela, S. S. I. (2000) en tablas donde compara de manera directa el pH versus la Saturación de las Bases y, confirmado por Arévalo (2016) en su caracterización de suelo en bosques de $A$. guatemalensis.

Por eso, condiciones como las encontradas para el fósforo, son las que obligaron a realizar aplicaciones de enraizadores al momento en que se estableció un experimento con plántulas de pinabete en el occidente de Guatemala (MartínezArévalo 2015).

La Capacidad de Intercambio Catiónico (CIC) obtenida en los 3 análisis se encuentra por encima del rango medio sugerido por Uviger (tablas 1 y 2), esto establece que posee una alta capacidad de retener cationes tales como Calcio, Magnesio, Potasio y Sodio, presentes en el suelo, debido a que hay un alto contenido de sustancias húmicas dentro de la materia orgánica existente en el suelo (Herrán, Torres \& Rojo 2008; Otero, Ortega \& Morales 1998). Lo cual aseveran León, González, \& Gallardo (2011) que son factores muy favorables para el crecimiento y desarrollo de plántulas de coníferas. Patrones mostrados en los presentes resultados de análisis químico de suelo tales como un contenido alto de materia orgánica, una baja saturación de las bases y un nivel de $\mathrm{pH}$ bajo son característicos de un proceso de sucesión vegetal que se presenta a lo largo de más de un siglo (Martínez-Arévalo 2013). 
En relación con el análisis físico del suelo hecho por parte de Uviger, se determinó que las 3 muestras tomadas dieron como resultado ser un suelo Franco Arenoso, lo cual coincide de manera directa con el mismo tipo de clase textural obtenida por Arévalo (2016); según Lorenz (1995) este tipo de textura ayuda para que se dé un mejor desarrollo de las plantas, ya que permite al pinabete tener mayor anclaje y penetrabilidad radicular, buena aireación y una alta capacidad para retención de agua. La roca madre, que es una limitante del desarrollo radicular al momento de encontrarse a distancias no muy profundas, se encontró a distancias mayores de $1.5 \mathrm{~m}$ de la superficie del mismo; de lo cual nos indica que los suelos en términos de profundidad son excelentes para el desarrollo del pinabete.

Los datos climáticos que se recopilaron fueron un poco escuetos, debido a lo difícil que fue la obtención de la estación meteorológica para su monitoreo; pero los 2 meses que se lograron recopilar indican que son climas ideales para el crecimiento y desarrollo de la especie en las partes altas de la aldea Soledad Grande. La hidrografía en el área en estudio se determinó que es fundamental la cobertura forestal y los bosques de pinabete y su sotobosque juegan un papel preponderante en la recarga hídrica de la cuenca.

En base a la generación de los mapas temáticos orientados a las áreas potenciales para restaurar, podemos indicar que según las altitudes encontradas en las hojas cartográficas de la aldea Soledad Grande, el área total a restaurar es de 2516.54 ha, descartando un área de 195.5 ha, debido a que son áreas en donde las altitudes no son apropiadas para el desarrollo y crecimiento del pinabete. En lo que respecta al mapa de plantas nodrizas, se detectaron 543.41 hectáreas con presencia de las mismas, por lo tanto, esa área es la adecuada para su restauración; ya que en ella se facilita el proceso de sucesión del pinabete. El mapa de red hídrica nos indica que es una zona de recarga hídrica; lo cual indica que se necesita de especies arbóreas como el pinabete para que contribuyan a dicha actividad. Dando soporte a la iniciativa de continuar con la reproducción del pinabete. Siendo más concretos y objetivos, podemos indicar que al momento de sobreponer los mapas de altitudes, de plantas nodrizas y de áreas con presencia de pinabete, el área con mayor potencial para la restauración de pinabete en la aldea Soledad Grande, Mataquescuintla, Jalapa se estima que es de 543.41 hectáreas, esto debido a que son áreas donde convergen la mayoría de las condiciones necesarias para que se desarrolle dicha especie, tomando en cuenta factores indispensables tales como altitud, profundidad de los suelos, existencia de plantas nodrizas, microclima ideal, zonas de recarga hídrica.

\section{Conclusiones}

Las potenciales plantas nodrizas que se identificaron, se deben analizar para su posterior inclusión en el nodrizaje. Siendo objeto de estudio los beneficios que se suponen están brindando al pinabete. De tal manera que si no contribuyen al proceso de sucesión deberán ser excluidas. Siendo este estudio un proceso a considerar, el cual conlleva un tiempo prudente y es de gran importancia para el crecimiento y desarrollo del pinabete, ya que sin la presencia de plantas nodrizas, se tiene comprobado (Martínez-Arévalo, 2015) que es muy baja la subsistencia del pinabete.

El área encontrada con presencia de pinabete es de 278.27ha, de lo cual es muy importante que se realicen labores de restauración para la recuperación de tan importante especie. Identificándose la presencia superior al $80 \%$ de hongos micorrícicos, suelos profundos con alto contenido de materia orgánica y con la mayoría de nutrientes a cantidades ideales; y datos climáticos de los meses de noviembre y diciembre del 2016.

Las áreas sujetas a restauración se encuentran en un estimado de 543.41 hectáreas, quedando esta cantidad sujeta a aumentar puesto que las fincas y terrenos cercanos presentan características ideales para la reproducción de pinabete.

Los suelos del área en estudio presentan una alta capacidad de retener cationes tales como calcio, magnesio, potasio y sodio, presentes en el suelo debido a que hay un alto contenido de sustancias 
húmicas dentro de la materia orgánica. Se determinó que las tres muestras tomadas dieron como resultado ser un suelo Franco Arenoso y este tipo de textura ayuda para que se dé un mejor desarrollo del pinabete, ya que posee características como un mayor anclaje y penetrabilidad radicular, buena aireación y una alta capacidad para retención de agua. Con estas características de suelo obtenidas, se tiene una base para identificar áreas apropiadas para iniciar un proceso de restauración ecológica pues con esta investigación se ha determinado las condiciones edáficas adecuadas para la reproducción, crecimiento y desarrollo de pinabete.

La germinación del pinabete ha sido un tema de mucha importancia dentro de las personas que se dedican a su estudio, ya que el porcentaje de éxito es muy bajo, por ende es una limitante que se debe combatir con el estudio de diversas técnicas y el uso de precursores germinativos que mejoren la viabilidad y porcentaje de germinación en la semilla del pinabete.

\section{Referencias}

Álvarez-Sanchez, M. E., Hernández-Acosta, E., Maldonado-Torres, R., \& Rivera-González, M. (2013). Encalado y micorriza para corregir deficiencia de fósforo en un Andisol cultivado con Pinus halepensis. Madera y bosques, pp. 7-16.

Apfelbaum, S. \& Haney, A. (2010). Restoring ecological health to your land. USA. Island Press. 240 p.

Arévalo, J. V. M. (2016). Los bosques de Abies guatemalensis Rehder de San Marcos, Guatemala: una oportunidad para su restauración ecológica. Ciencia, Tecnología y Salud, pp. 27-46.

Bello, C. H. Á., \& López-Mata, L. (2001). Distribución y análisis estructural de abies hickelii (flous \& gaussen) en México. Interciencia, pp. 244-251.

Bernier, R. (2014). Capacitación para operadores de programa de recuperación de suelos degradados. Técnicas de muestreo de suelo para análisis de fertilidad, INDAP. Chile. 116p.

Cairns Jr, J., \& Heckman, J. R. (1996). Restoration ecology: the state of an emerging field. Annual Review of Energy and the Environment, pp. 167-189.

Choi, Y. et al. (2008). Ecological restoration for future sustainability in a changing environment. Ecoscience, 15(1), 53-64.

Clewell, A.F. y Aronson, J. (2007). Ecological restoration: principles, values, and structure of an emerging profession. Washington, USA, Island Press, pp. 75-85.

Cardona, N. (2005). Consideraciones socioeconómicas en el diseño proyectos sustentables de restauración ecológica. En Sánchez, O., et al. (Eds.). Temas sobre restauración ecológica. México D.F.: Instituto Nacional de Ecología. pp. 45-56.

Davis, M. A., \& Slobodkin, L. B. (2004). The science and values of restoration ecology. Restoration Ecology, pp. 1-3.

Herrán, J. A. F., Torres, R. R. S., \& Rojo, G. E. (2008). Importancia de los abonos orgánicos. Ra Ximhai, pp. 57-67.

León, J. D., González, M. I., \& Gallardo, J. F. (2011). Ciclos biogeoquímicos en bosques naturales y plantaciones de coníferas en ecosistemas de alta montaña de Colombia. Revista de Biología Tropical pp. 1883-1894.

Lorenz, G. (1995). Caracterización ecológica de un suelo Eutric Regosol bajo bosque en el Chaco Semiárido, Argentina. Quebracho, pp. 13-23.

Martínez-Arévalo, J. V. (2013). Sucesión ecológica secundaria alrededor de parches de bosque con pinabete (Abies guatemalensis Rehder) en San Marcos, Guatemala. 
Martínez-Arévalo, J. V. (2015). Conocimiento de seis especies arbustivas utilizadas como plantas nodrizas en el occidente de Guatemala. Ciencia, Tecnología y Salud, pp, 15-27.

Morón, A., \& La Estanzuela, S. S. I. (2000). Alfalfa: Fertilidad de suelos y estado nutricional en sistemas agropecuarios de Uruguay. Informaciones Agronómicas del cono sur, pp. 1-6.

Otero, L., Ortega, F., \& Morales, M. (1998). Participación de la arcilla y la materia orgánica en la capacidad de intercambio catiónico de vertisoles de la provincia Granma. Terra, 16(3), 16.

Palmer, M. A., Ambrose, R. F., \& Poff, N. L. (1997). Ecological theory and community restoration ecology. Restoration ecology, pp. 291-300.

Pinochet, F. (1991). Los suelos forestales de la Región del Maule. Universum, 6. Recuperado de http://universum.utalca.cl/contenido/index-91/ Fernando_Pinochet.html

Rossiter, D. G., \& ROJAS, R. V. (2002). Metodologías para el levantamiento del recurso suelo. Traducido al espanol por Ronald Vargas.

SER (Society for Ecological Restoration International Science \& Policy Working Group). (2004). The SER International Primer on Ecological Restoration.

Vargas, O. (2011). Restauración ecológica: Biodiversidad y Conservación. Acta biol. Colomb, pp. 221-246.

Winterhalder, K., Clewell, A. F., \& Aronson, J. (2004). Values and science in ecological restoration-a response to Davis and Slobodkin. Restoration Ecology, pp. 4-7. 